EESTI NSV TEADUSTE AKADEEMIA TOIMETISED. XI KÖIDE

FOUSIKALIS-MATEMAATILISTE JA TEHNILISTE TEADUSTE SEERIA. 1962, NR. 3

ИЗВЕСТИЯ АКАДЕМИИ НАУК ЭСТОНСКОН ССР. ТОМ ХІ

СЕРИЯ ФИЗИКО-МАТЕМАТИЧЕСКИХ И ТЕХНИЧЕСКИХ НАУК. 1962, № 3

\title{
ОЧИСТКА И ФРАКЦИОНИРОВАНИЕ СМЕСЕЙ НАСЫЩЕННЫХ ДИКАРБОНОВЫХ КИСЛОТ, ПОЛУЧЕННЫХ ОКИСЛЕНИЕМ КЕРОГЕНА СЛАНЦА-КУКЕРСИТА
}

\author{
Л. ПОБУЛЬ, А. ФОМИНА, \\ кандидаты технических наук
}

При окисленин органического вещества (керогена) эстонского горючего сланцакукерсита щелочным раствором перманганата калия ['] или азотной кислотой [2] образуется смесь кислых соединений различной сложности. Среди них преобладающее место занимают насыщенные дикарбоновые кислоты, которые являются и самыми ценными продуктами окисления, так как они представляют из себя сырье для производства различных пластмасс, полиэфирных смазочных масел и мягчителей.

По данным Всесоюзного института пластических масс, для пластифицирования пюливинилхлоридной смолы пригодна только фракция кислот $\mathrm{C}_{6}-\mathrm{C}_{10}$, но это отно сится к сложным эфирам 2-этилгексилового спирта. По литературным данным, для изготовления полиэфирных пластификаторов на основе двух- и более атомных спиртов пригодна широкая смеси кислот, начиная от янтарной $\left[{ }^{3}, 4\right]$. Смесь кислот $\mathrm{C}_{4}-\mathrm{C}_{10}$ также является хорошим сырьем для получения эфирных смазочных масел [5] и т. д.

Можно было бы привести много других областей применения, например, Чандлер [ $\left.{ }^{6}\right]$ считает, что полиэфиры - покрытия будущего. Однако для использования их в любой из областей синтеза необходимо иметь чистые кислоты. Они не должны содержать примесей побочных продуктов окисления и в случае использования в качестве окислителя азотной кислоты, остатков окислителя и органических азотсодержащих соединений.

При окисленни анола (смесь циклогексанол-циклогексанона) азотной кислотой хотя и получается смесь кислот $\mathrm{C}_{2}-\mathrm{C}_{6}$, но основным продуктом является легко кристаллизующаяся адипиновая кислота, очистка которой в промышленности осуществляется сравнительно несложными путями. Другое дело, когда в качестве целевого продукта получается смесь кислот, как, например, из керогена горючего сланца, $\mathrm{C}_{4}-\mathrm{C}_{10}$ или из смеси парафиновых углеводородов (мягких и твердых парафинов) до пробковой включительно [7], или как получено в работах группы Б. Л. Молдавского [8.9], при окислении оксидата воздушного окисления парафина азотной кислотой, смеси кислот от $\mathrm{C}_{4}$ до $\mathrm{C}_{10}$. Во всех трех приведенных случаях получаются смеси, в которых ни одна из кислот значительно не превалирует по содержанию. Кроме того, при получении адипиновой кислоты в составе образующейся смеси в небольшом количестве получается только одна кислота с нечетным числом углеродных атомов - глутаровая (малоновая кислота разрушается в процессе окисления), а в вышеуказанных смесях значительная доля падает на кислоты $\mathrm{C}_{5}, \mathrm{C}_{7}, \mathrm{C}_{9}$. В результате этого получаюцаяся смесь кислот не может быть выделена простой кристаллизацией. Она, вместе с побочными продуктами окисления, остается в растворе отработанной азотной кислоты. После отгонки окислителя получается смолистого вида (окрашенная в 
оранжевый цвет) масса, из которой целевые кислоты - насыщенные дикарбоновые кислоты - должны извлекаться органическим растворителем. При экстракции целевых кислот вместе с ними извлекаются все же и примеси. Так, сырая смесь кислот, полученная из растворимых в слабой азотной кислоте продуктов окисления керогена дихлорэтаном, содержит от 10 до $20 \%$ примесей. При экстракции этиловым эфиром или ацетоном количество примесей заметно увеличивается.

Получение насыщенных дикарбоновых кислот из более дешевых источников сырья в виде смесей представляет большой промышленный интерес. В связи с этим в ряде стран уделяется значительное внимание вопросу очистки и разделения смесей кислот на фракции и индивидуальные кислоты. В патентной литературе имеется немало рекомендаций для этого, но до сих пор еще нет удовлетворительных способов, которые в действительности можно было бы рекомендовать промышленности. Так, Хигучи Такеру запатентовал, в качестве промышленного способа очистки и разделения смеси на индивидуальные кислоты, фактически аналитический способ распределительной хроматографии на силикагеле [10]. Несомненно этот способ совершенно непригоден для промышленных условий в том виде, в каком он предлагается в американском патенте.

С целью разработки приемлемого способа очистки и разделения смеси насыщенных дикарбоновых $\mathrm{C}_{4}-\mathrm{C}_{10}$, получающихся при окислении керогена кукерсита, был опробован ряд способов, основные результаты которых могут представить интерес при получении смесей кислот и из других сырьевых источников. Для исследования использовались сырые смеси кислот, полученные в процессах окисления керогена кукерсита как щелочным перманганатом калия, так и азотной кислотой. Кислоты извлекались из продуктов окисления этиловым эфиром.

Ниже излагаются основные результаты исследований по трем способам: 1) очистка и разделение кислот через получение сложных эфиров; 2) очистка и разделение путем вакуумной дистилляции с перекристаллизацией дистиллированных кислот; 3) очистка и разделение кислот на силикагелевых колоннах.

\section{1. Очистка и разделение смеси кислот через получение сложных эфиров}

Для идентификации продуктов окисления органических соединений наиболее применяемым методом является этерификация $\left[{ }^{11},{ }^{12},{ }^{13},{ }^{14}\right]$. Ректификацией смеси эфиров с последующим омылением полученных фракций некоторыми авторами выделены чистые кислоты, как янтарная и адипиновая [12].

Большинство исследователей для этого приготовляют диметиловые эфиры, которые имеют самую низкую температуру кипения. При этерификации метиловым спиртом для получения лучшего выхода надо применять вспомогательные растворители (толуол, ксилол), с помощью которых образовавшаяся вода все время удаляется из реакционной смеси.

Проще и лучше протекает этерификация бутиловым спиртом. Последний сам дает с в́дой азеотропную смесь и, таким образом, является сам водбудаляющим вешеством.

С целью разделения дикарбоновых насыщенных кислот, образовавшихся в процессе окисления керогена кукерсита, из них были синтезированы дибутиловые эфиры. Максимальный выход последних составлял 99\% от теоретического. Полученные дибутиловые эфиры подвергались фракционированию ректификацией в вакууме (при 2 мм pt. ст.). Использованная ректификационная колонка имела 26 теоретических тарелок, число которых было определено по разделению смеси дихлорэтан-бензол [15]. Выход при дистилляции составлял $92,6 \%$, остаток $3,2 \%$ и потери $4,2 \%$.

Полученные фракции подвергались омылению. Освобождавшиеся кислоты экстрагировались этиловым эфиром, и количество насыщенных дикарбоновых кнслот в экстракте определялось хроматографическим методом [16]. Из данных табл. 1 видно, 
что при омылении фракции, выкипающей до $118^{\circ}$, получается янтарная кислота и соединение с более короткой цепью, которое в ходе хроматографического анализа не элюируется из колонки раствором н-бутилового спирта в хлороформе. Последнее соединение в исходном веществе отсутствовало. Фракции, выкипающие в пределах

Таблича 1

Выход и состав кислот, выделенных омылением дибутиловых эфиров из фракций вакуумной дистилляции

\begin{tabular}{|c|c|c|c|c|c|c|c|c|c|c|}
\hline \multirow[b]{2}{*}{ 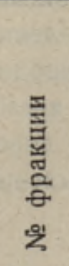 } & \multirow{2}{*}{ 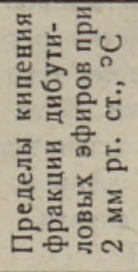 } & \multirow{2}{*}{ 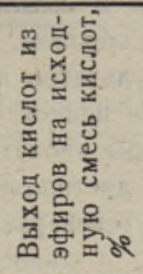 } & \multicolumn{8}{|c|}{$\begin{array}{c}\text { Компонентный состав полученных кислот по } \\
\text { хроматографическому анализу, \% }\end{array}$} \\
\hline & & & 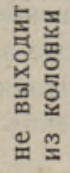 & $\mathrm{C}_{4}$ & $C_{5}$ & $\mathrm{C}_{6}$ & $\mathrm{C}_{7}$ & $\mathrm{C}_{8}$ & $\mathrm{C}_{9}$ & $\mathrm{C}_{10}$ \\
\hline $\begin{array}{l}\text { I } \\
\text { II } \\
\text { III } \\
\text { IV } \\
\text { V } \\
\text { VI }\end{array}$ & $\begin{array}{r}97-115 \\
115-118 \\
118-128 \\
128-140 \\
140-150 \\
150-210\end{array}$ & $\begin{array}{r}2,8 \\
9,9 \\
13,5 \\
13,3 \\
4,7 \\
29,9\end{array}$ & $\begin{array}{c}86,0 \\
58,0 \\
- \\
-\end{array}$ & $\begin{array}{r}14,0 \\
40,0 \\
82,0 \\
16,5 \\
3,2 \\
6,6\end{array}$ & $\begin{array}{r}\overline{-} \\
\overline{7} \\
9,0 \\
47,7 \\
25,6 \\
8,7\end{array}$ & $\begin{array}{r}\overline{1} \\
9,2 \\
9,0 \\
35,8 \\
73,0 \\
16,8\end{array}$ & $\begin{array}{l}\overline{-} \\
\overline{-} \\
\overline{25,8}\end{array}$ & $\begin{array}{l}\bar{z} \\
\overline{-} \\
\overline{14,7}\end{array}$ & $\begin{array}{l}- \\
\overline{-} \\
\overline{-} \\
\overline{12}, 7\end{array}$ & $\begin{array}{l}\bar{z} \\
\bar{z} \\
\overline{14,7}\end{array}$ \\
\hline
\end{tabular}

$118-150^{\circ}$, состояли из смеси дибутиловых эфиров янтарной, глутаровой и адипиновой кислот, причем с повышением температуры кипения количество низших компонентов уменьшается, количество высших компонентов увеличивается. Фракция, выкипающая при температуре выше $150^{\circ}$, содержит все кислоты, содержащиеся в исходной смеси, в том числе и янтарную кислоту, хотя дибутиловый эфир янтарной кислоты имеет температуру кипения $145^{\circ}$ при вакууме 4 мм рт. ст. Выделенные после омыления кислоты представляли собой кристаллические вещества светло-желтого цвета. Послед-

\section{таблица 2}

Компонентный состав смеси исходных кислот и кислот, полученных из дибутиловых эфиров

\begin{tabular}{|c|c|c|c|}
\hline $\begin{array}{c}\text { Наимено- } \\
\text { вание кислоты }\end{array}$ & 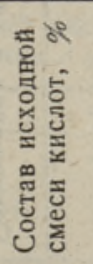 & 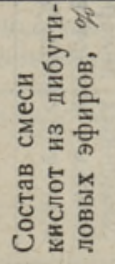 & 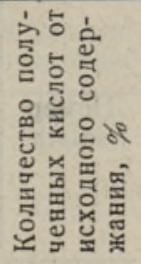 \\
\hline $\begin{array}{l}\text { Янтарная } \\
\text { Глутаровая } \\
\text { Адипиновая } \\
\text { Пимелиновая } \\
\text { Пробковая } \\
\text { Азелаиновая } \\
\text { Себациновая } \\
\text { и примеси }\end{array}$ & $\begin{array}{r}18,5 \\
21,7 \\
22,5 \\
14,2 \\
8,6 \\
7,4\end{array}$ & $\begin{array}{r}19,7 \\
11,2 \\
14,4 \\
7,7 \\
4,4 \\
3,9 \\
4,4 \\
\end{array}$ & $\begin{array}{r}106,5 \\
51,7 \\
64,0 \\
54,2 \\
51,2 \\
52,7\end{array}$ \\
\hline Bcero & 100,0 & 65,7 & \\
\hline
\end{tabular}


няя фракция содержала кроме насыщенных дикарбоновых кислот примеси в количестве около $5 \%$.

Результаты данной работы, а также опыты Робинзона [14] показывают, что ректификация смесей сложных эфиров дикарбоновых кислот не дает индивидуальных кислот. При этом образуются азеотропные смеси различного компонентного состава с широким распределением эфиров индивидуальных кислот по фракциям. Сравнением компонентного состава исходной смеси с составом кислот, полученных омылением (табл. 2), установлено уменьшение количества всех компонентов, за исключением янтарной кнслоты, количество которой даже увеличивалось. Из полученных данных можно сделать вывод, что в ходе фракционирования и омыления эфиров происходит декарбоксилирование и окисление кислот. Таким образом, очистка и разделение кислот через сложные эфиры не дает ожидаемых результатов и кроме того приводит к значительным потерям кислот $\mathrm{C}_{6}-\mathrm{C}_{10}$, т. е. наиболее ценной части. В то же время сам процесс очистки и разделение через сложные эфиры является сравнительно дорогим, так как требует ряда операций: этерификации, дистилляции эфиров, омыления 9фиров, выделения кислот из продуктов омыления и регенерации спирта.

\section{2. Очистка и разделение смеси кислот вакуумной дистилляцией с последующей перекристаллизацией}

Известно, что даже чистые дикарбоновые кислоты при нагревании способны к различного рода превращениям, ангидридизации, декарбоксилированию и т. д. Тем более этсго можно было ожидать в присутствии примесей.

Для вакуумной дистилляции были использованы сырые кислоты с различным содержанием неэлюирующихся примесей. Дистилляция проводилась в среде инертных газов (азот или двуокись углерода) из колбы Кляйзена. Несмотря на то, что до начала дистилляции вакуум составлял 2-3 мм рт. ст., к началу дистилляции вакуум падал до 11-12 мм. При этом давлении при температуре около $100^{\circ}$ начиналась медленная дистилляция. После завершения реакций разложения основная масса кислот перегонялась при остаточном давлении около 2 мм рт. ст. в пределах температур $170-200^{\circ}$.

Результаты первой серии дистилляций сырых смесей кислот приведены в табл. 3.

\section{Таблица 3}

\section{Результаты вакуумной перегонки сырых кислот $\mathrm{C}_{4}-\mathrm{C}_{10}$ из колбы Кляйзена}

\begin{tabular}{|c|c|c|c|c|}
\hline $\begin{array}{l}\text { Номер } \\
\text { опыта }\end{array}$ & 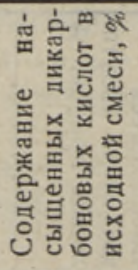 & 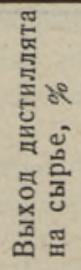 & 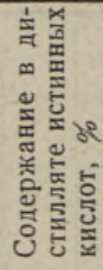 & 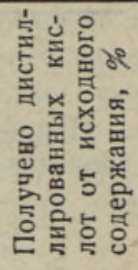 \\
\hline I & 93,0 & 78,0 & 94,5 & 79,0 \\
\hline II & 81,5 & 65,0 & 86,8 & 69,7 \\
\hline III & 80,5 & 66,4 & 86,2 & 71,0 \\
\hline IV & 61,0 & 45,7 & 76,1 & 57,0 \\
\hline
\end{tabular}

Полученные результаты показали, что чем больше в сырых смесях кислот находится примесей, тем больше теряется в .результате вакуумной перегонки истинных дикарбоновых куслот. Хроматографический анализ продуктов дистилляции позволил 
установить потери индивидуальных кислот. Такой расчет для крайних по содержанию примесей сырцх кислот приведен в табл. 4. Полученные результаты показывали, что во всех случаях основные потери приходятся на янтарную кислоту. Частично, очевидно, за счет потери в виде янтарного ангидрида. Однако чем меньше примесей, тем все же меньше потери и янтарной кислоты.

\section{Таблица 4}

\section{Выход индивидуальных кислот при дистилляции в зависимости от состава исходного сырья}

\begin{tabular}{l|c|c}
\hline \multirow{2}{*}{$\begin{array}{c}\text { Наименова- } \\
\text { ние кислот }\end{array}$} & \multicolumn{2}{|c}{$\begin{array}{c}\text { Выходы отдельных компонентов } \\
\text { от исходного количества, \% }\end{array}$} \\
\cline { 2 - 3 } & $\begin{array}{c}\text { Опыт I } \\
\text { (табл. 3) }\end{array}$ & $\begin{array}{c}\text { Oпыт IV } \\
\text { (табл. 3) }\end{array}$ \\
\hline Янтарная & 48,8 & 31,9 \\
Глутаровая & 70,0 & 52,3 \\
Адипиновая & 92,0 & 55,0 \\
Пимелиновая & 88,6 & 63,4 \\
Пробковая & 96,4 & 74,5 \\
Азелаиновая & 96,2 & 85,0 \\
Себациновая и & 91,0 & 79,3 \\
\hline примеси & 79,0 & 57,0 \\
Общий выход &
\end{tabular}

При содержании в сырых кислотах около $10 \%$ примесей потери целевых кислот в количестве $20 \%$ можно считать вполне удовлетворительными. Тем более, что основные потери падают на менее ценные, низшие компоненты смеси, а выход кислот $\mathrm{C}_{6}-\mathrm{C}_{10}$ в среднем составляет свыше $90 \%$ от первоначального их количества. При этом кислоты содержат только около 5\% примесей, которые можно удалить уже перекристаллизацией. Однако полученный дистиллят кислот представляет всю смесь $\mathrm{C}_{4}-\mathrm{C}_{10}$. С целью определения возможности получения более узких по компонентному составу фракций была проведена вторичная ректификация дистиллята в колонке, которая имела 6 теоретических тарелок. Вторичная дистилляция протекала без за-

таблица 5

Характеристика фракций кислот, полученных в результате вторичной дистилляции с ректификационной колонкой

\begin{tabular}{|c|c|c|c|c|c|c|c|c|c|c|c|}
\hline \multirow{2}{*}{ 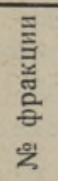 } & \multirow{2}{*}{ 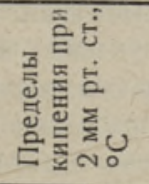 } & \multirow{2}{*}{ 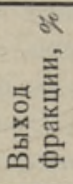 } & \multirow{2}{*}{ 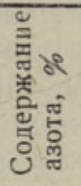 } & \multicolumn{8}{|c|}{ Компоненгный состьв, \% } \\
\hline & & & & $\mathrm{C}_{4}$ & $\mathrm{C}_{5}$ & $\mathrm{C}_{6}$. & $\mathrm{C}_{7}$ & $\mathrm{C}_{8}$ & $\mathrm{C}_{9}$ & $\mathrm{C}_{10}$ & 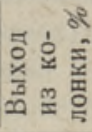 \\
\hline $\begin{array}{r}\text { I } \\
\text { II } \\
\text { III }\end{array}$ & $\begin{array}{l}100-165 \\
165-177 \\
177-193\end{array}$ & $\begin{array}{r}21,3 \\
7,5 \\
57,4\end{array}$ & $\begin{array}{l}2,2^{*} \\
0,5 \\
0,3\end{array}$ & $\begin{array}{r}33,3 \\
1,7 \\
-\end{array}$ & $\begin{array}{l}48,0 \\
35,2 \\
11,5\end{array}$ & $\begin{array}{l}11,0 \\
17,2 \\
41,1\end{array}$ & $\begin{array}{r}1,0 \\
3,0 \\
24,4\end{array}$ & $\begin{array}{r}3,9 \\
1,2 \\
12,6\end{array}$ & $\begin{array}{l}\overline{3,7} \\
5,0\end{array}$ & $\begin{array}{l}3,0 \\
7,3 \\
5,4\end{array}$ & $\begin{array}{r}100,0 \\
69,3 \\
100,0\end{array}$ \\
\hline & $\begin{array}{c}\text { Остаток в } \\
\text { колбе } \\
\text { Потери }\end{array}$ & $\begin{array}{r}11,8 \\
2,0\end{array}$ & 1,5 & & & & & & & & \\
\hline
\end{tabular}

* Исходные сырые кислоты содержали $1,8 \%$ азота. 
метного разложения при остаточном давлении около 2 мм рт. ст. В результате этой разгонки были получены три фракции кислот с выходом $86,2 \%$ на первый суммарный дистиллят или $67,0 \%$ на смесь сырых кислот. Полученные фракции были охарактеризованы по содержанию азота и компонентному составу. Результаты анализа приведены в табл. 5 .

Из приведенных данных видно, что в результате вторичной дистилляции полу. пены две фракции кислот, которые могут быть охарактеризованы - первая, как конщентрат низших кислот $\mathrm{C}_{4}-\mathrm{C}_{5}$ и третья, не содержащая янтарной кислоты, как концентрат кислот $\mathrm{C}_{6}-\mathrm{C}_{10}$. Промежуточная вторая фракция аккумулирует основные летучие примеси и по составу истинных кислот примыкает ближе к концентрату низших кислот $\mathrm{C}_{4}-\mathrm{C}_{5}$. Однако полученные кислоты, в особенности первая фракция, включают в себя также азотсодержащие соединения и поэтому остаются непригодными для синтезов. При перекристаллизации первой и третьей фракции кислот из дихлорэтана получаются смеси кнслот, свободные от азота. Таким образом, в результате двухкратной дистилляции можно получить две фракции кислот, которые могут иметь различное назначеңие. Однако вторичная фракционная дистилляция значительно увеличивает потери истинных кислот. Поэтому более целесообразным является использование всей смеси кислот с применением однократной перегонки, целью которой является отделение истинных дикарбоновых кислот от побочных продуктов окисления н нитрования, с последующей перекристаллизацией их для окончательной очистки от вязких азотсодержащих соединений.

Дальнейшими опытами было установлено, что промежуточная фракция и маточник перекристаллизации также могут быть использованы для последующей дистилляции, а в промышленных условиях потери вещества должны быть более низкими. В заключение данного раздела исследований можно прийти к выводу, что вакуумная дистилляция в комбинации с перекристаллизацией дистиллированных кислот может служить основой для разработки промышленного способа очнстки сырых смесей кислот для технически чистого продукта.

\section{3. Очистка и разделение кислот на силикагелевых колонках}

Распределительная хроматография на силикагеле в качестве аналитического ме. тода весьма удобна. Она дает возможность одновременно получить качественные и количественные результаты. В ряде областей промышленной химии силикагель уже используется для разделения смесей и на производстве. Поэтому весьма заманчивым представлялось использовать силикагель для очистки и разделения сырых смесей насыщенных дикарбоновых кислот $\mathrm{C}_{4}-\mathrm{C}_{10}$. В качестве аналитического метода распределительная хроматография используется в исследовании в те чение уже ідлительного времеми, но для промышленного применения аналитическая методика непригодна. Во-первых, потому что для получения четкого разделения смеси на индивидуальные компоненты берется очень большое соотношение силикагель: анализируемая смесь примерно 140:1 по весу. Во-вторых, для выделения индивидуальных кислот всего ряда требуется две колонки, причем вторая, на которой разделяются кислоты $\mathrm{C}_{7}-\mathrm{C}_{10}$, работает однократно. В-третьих, для выделения всех кислот в виде индивидуальных соединений требуется наличие целой серии элюэнтов, представляющих различной концентрации растворы н-бутилового спирта в хлороформе. Поэтому ранее цитированный патент Такеру Хигучи совершенно неприемлем в производственных условиях. Представлялось целесообразным изучить возможность использования силикагеля с частичным применением аналитического метода, именно только первой его части (1 колонка), где можно произвести разделение смеси $\mathrm{C}_{4}-\mathrm{C}_{10}$ на две фракция $\mathrm{C}_{4}-\mathrm{C}_{6}$ и $\mathrm{C}_{7}-\mathrm{C}_{10}$. Для исследований прнменялся силикагель отечественных марок АСК и КСМ в соотношении 1:1. Колонка заполнялась сухим способом [17]. 
Опыты проводились на малой колонке с загрузкой силикагеля в количестве $30 \mathrm{r}$. Для разделения использовались 2 и $5 \%$-ые растворы сырых кислот в $1 \%$-ом растворе третичного бутанола в хлороформе.

При разделенин кислот на две фракции $\mathrm{C}_{4}-\mathrm{C}_{6}$ и $\mathrm{C}_{7}-\mathrm{C}_{10}$, последняя проходила через колонки вместе с растворителем. Для контроля состава кислот от каждых 50 мл выходящего из колонки раствора отбиралась 5 мл проба. для анализа на отдельной колонке,

Полученные результаты для первой фракции приведены в табл. 6. Для удаления кислот $\mathrm{C}_{4}-\mathrm{C}_{6}$ использовалась вода.

\section{Таблица 6}

\section{Состав проходящей через колонку части кислот в зависимости от концентрации и количества пропущенной через силикагель смеси}

\begin{tabular}{|c|c|c|c|c|c|}
\hline \multirow{2}{*}{ 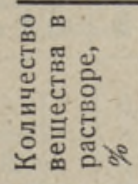 } & \multirow{2}{*}{ 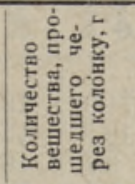 } & \multicolumn{4}{|c|}{$\begin{array}{l}\text { Компонентный состав } \\
\text { растворов кислот, \% }\end{array}$} \\
\hline & & $\mathrm{C}_{4}$ & $\mathrm{C}_{5}$ & $\mathrm{C}_{6}$ & $\begin{array}{c}\mathrm{C}_{7} \text { и } \\
\text { высшие }\end{array}$ \\
\hline $\begin{array}{l}2 \\
2 \\
5 \\
5 \\
5 \\
\end{array}$ & $\begin{array}{l}10 \\
12,5 \\
5 \\
10 \\
12,5\end{array}$ & $\begin{array}{l}\overline{1,0} \\
1,2 \\
1,8 \\
2,5\end{array}$ & $\begin{array}{l}\overline{2,5} \\
2,1 \\
3,2 \\
5,1\end{array}$ & $\begin{array}{r}2,4 \\
6,8 \\
9,7 \\
11,8 \\
12,1\end{array}$ & $\begin{array}{l}32,6 \\
33,2 \\
25,4 \\
33,8 \\
34,1\end{array}$ \\
\hline $\begin{array}{l}\text { Состав } \\
\text { смеси }\end{array}$ & $\begin{array}{l}\text { исходной } \\
\text { кислот }\end{array}$ & 16,5 & 18,0 & 17,0 & 36,7 \\
\hline
\end{tabular}

Опыт показал, что при использовании $2 \%$-ого раствора кислот можно при соотношении разделяемых кислот к силикагелю $1: 3$ получить фракцию кислот, свободную от низших компонентов $\mathrm{C}_{4}-\mathrm{C}_{5}$. $5 \%$-ый раствор кислот даже при соотношени $1: 6$ этого эффекта не дает.

Балансовый опыт был проведен на $4 \%$-ом растворе кислот. Для большей гарантии удаления из колонки кислот выше глутаровой в балансовом опыте до промывки водой был использован $10 \%$-ый раствор н-бутанола в хлороформе. При этом смесь распределилась на три фракции:

1. С растворителем через колонку прошло $65 \%$ нсходных кислот.

2. $10 \%$-ым н-бутанолом было элюировано $9 \%$ кислот.

3. Водой вымыто $26 \%$ нсходных кислот.

Характеристика полученных фракций и выход кислот от исходного их количества иллюстрируются данными табл. 7.

Приведенные данные показывают, что даже 4\%-ый раствор является слишком концентрированным для того, чтобы получить четкое разделение на низшие компоненты $\mathrm{C}_{4}-\mathrm{C}_{6}$ и высшие $\mathrm{C}_{7}-\mathrm{C}_{10}$. Это указывает на необходимость пропуска чрезмерно больших объемов растворителя, что в производственных условиях было бы весьма обременительным. Кроме того, в смеси оказывается больше примесей и увеличивается общий выход. Это можно отнести за счет образования эфиров бутилового спирта. При попытке использовать для растворения кислот н-бутанол основная часть их после прохождения силикагелевой колонки оказалась этерифицированной. Все эти недостатки указывали на то, что очистка и разделение кислот на силикагеле очень сложна и громоздка даже в том упрощении аналитического метода, которое было применені.

Тем не менее очистка и разделение кислот на адсорбентах представляет интерес и должна разрабатываться - она не бесперспективна. Таким образом, из трех опробованных методов наиболее осуществимым в ближайшее время оказался метод ва- 
куумной дистилляции с последующей перекристаллизацией дистиллированных кислот из дихлорэтана. В особенности он удовлетворителен для очистки смеси кислот $\mathrm{C}_{4}-\mathrm{C}_{10}$ без разделения ее на фракции низших и высших компонентов смеси.

\section{Таблица 7}

Выход и состав кислот после очистки и разделения смеси на силикагеле

\begin{tabular}{|c|c|c|c|c|c|}
\hline 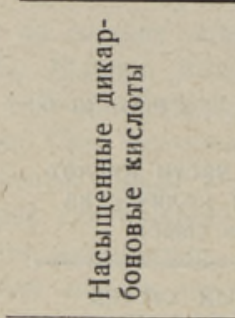 & 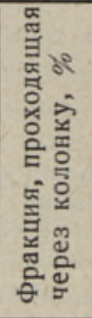 & 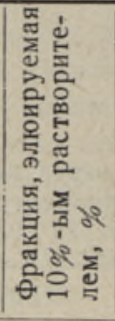 & 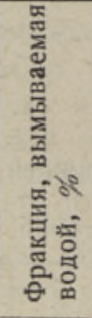 & 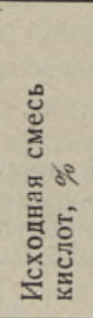 & 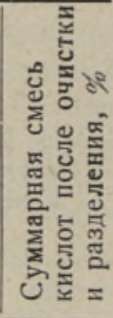 \\
\hline $\begin{array}{l}\mathrm{C}_{4} \\
\mathrm{C}_{5} \\
\mathrm{C}_{6} \\
\mathrm{C}_{7} \text { и выше } \\
\end{array}$ & $\begin{array}{l}\overline{10,2} \\
20,8 \\
39,0\end{array}$ & $\begin{array}{l}12,5 \\
27,4 \\
26,8 \\
25,2\end{array}$ & $\begin{array}{r}71,0 \\
13,2 \\
3,7 \\
+1,0 \\
\end{array}$ & $\begin{array}{l}18,8 \\
15,8 \\
18,3 \\
30,7 \\
\end{array}$ & $\begin{array}{l}19,6 \\
12,6 \\
16,9 \\
27,7 \\
\end{array}$ \\
\hline $\begin{array}{l}\text { Выход из ко- } \\
\text { лонки }\end{array}$ & 70,0 & 91,9 & 88,9 & 83,6 & \\
\hline
\end{tabular}

\section{ЛИТЕРА Т У РА}

1. А. С. Фомин а, Л. Я. Побуль. Окислительная деструкщия керогена кукерсита, Изв. АН ЭССР, 1955, т. IV, № 4, стр. 587.

2. 3. А. Д е г т е р в а, А. С. Фомин а. Химическая переработка сланца-кукерсита на двухосновные насыщенные кислоты $\mathrm{C}_{4}-\mathrm{C}_{10}$, Изв. АН ЭССР, 1959, т. VIII, сер. техн. н физ.-матем. наук, № 2, стр. 123.

3. D. H. C of f e y, E. A. P a cke r. Англ. пат. 773986, 1. 05.57.

4. B. D. A itke n, D. H. C of f e y, E. A. Р a c ke r. Англ. пат. 744831, 15. $02 . .56$.

5. E. I. K row le y, H. J. Eld e r, N. W. Fra n k. Пат. США 2815358, 3. 12. 57.

6. R. H. Chandler. Paint. Manufact. 1958, 28, No. 5, 141.

7. C. N. Z ell ner, F. Lister, Ind, and Eng. Chemistry, 1956, No. 10, 1338.

8. Б. Л. Молд а с ки й, М. В. Блинова, В. Т. Бабель, Е. Я. Буслович и М. Ш. У см анов а. Получение двухосновных кислот окислением єоксикнслот» азотной кислотой, ЖПХ, 1960, с. 33, № 2, 463.

9. Б. Л. Молда в ски й. Получение дикарбоновых кислот из оксикислот, Химическая промышленность, 1960, № 2, 24.

10. Higuchi Takery, Пат. США, 2744067, 1. 05.56.

11. W. A. B one, G. B. Parsons, R. H. S a piro and C. M. Groocock. Prog. Soc., A., 1935, vol. 148, p. 492.

12. В. А. Л ан ин, М. В. П ронин а. Об органическом веществе горючих сланцев, Изв. АН СССР, ОТН, 1944, № 10-11, стр. 745.

13. E. D. Holly, R. S. Mont g o mer y. Fuel 1956, vol. XXXV, No. 1, p. 45.

14. W. E. R obin son, I. I. Cum m in s, K. E. S t a n f i eld. Industrial and Engineering Chemistry 1956, vol. 48 , No. 7 , p. 1134.

15. А. Я. Берлин. Техника лабораторной работы в органической химии, стр. 131. Госхимиздат. М.-Л., 1952.

16. А. С. Фомин а, Л. Я. Побуль. Окислительная деструкцня керогена кукерсита, Изв. АН ЭССР, 1955, т. IV, № 1, стр. 48.

17. П. Я. Побуль, А. С. Фомин а, 3. А. Д егтерев а. Анализ смесей дикарбоновых кислот методом распределительной хроматографин на силикагеле, Химия и технология топлив н масел. 1961, 10, стр. 55 . 


\title{
POLLEVKIVI KEROGEENI OKSUDEERIMISEL SAADAVATE KULLASTATUD DIKARBOONHAPETE PUHASTAMISEST JA ERALDAMISEST
}

\author{
L. Pobul, A. Fomina, \\ tehniliste teaduste kandidaadid
}

\section{Resümee}

Et välja selgitada kõige efektiivsemat meetodit põlevkivi kerogeeni oksüdeerimisel leeliseses või hapus $\left(\mathrm{HNO}_{3}\right)$ keskkonnas saadavate küllastatud dikarboonhapete $\mathrm{C}_{4}-\mathrm{C}_{10}$ puhastamiseks ja eraldamiseks, uuriti neist järgnevaid: hapete puhastamine ja eraldamine 1) nende estrite kaudu, 2) vaakuumdestillatsioonil koos järgneva ümberkristalliseerimisega ja 3) silikageeliga täidetud kolonnides.

Selgus, et käesoleval ajal on neist meetoditest kõige perspektiivsem vaakuumdestillatsioon, kusjuures puhaste hapete saagis on seda suurem, mida vähem lisandeid sisaldavad toorhapped.

\section{Eesti NSV Teaduste Akadeemia Keemia Instituut}

Saabus toimetusse

19. X 1961

\section{PURIFICATION AND FRACTIONING OF MIXTURES OF SATURATED DICARBONIC ACIDS OBTAINED AT THE OXIDATION OF KUKERSITE KEROGEN}

\author{
L. Pobul, A. Fomina
}

\section{Summary}

The authors present data on the purification and fractioning of mixtures of saturated dicarbonic acids $\mathrm{C}_{4}-\mathrm{C}_{10}$ obtained at the oxidation of the kerogen of Estonian oil shale kukersite, in alkaline and acid media $\left(\mathrm{HNO}_{3}\right)$. Three methods have been studied: 1) purification and fractioning of acids by synthesis of compound ethers; 2) purification and fractioning by vacuum distillation with re-crystallization of the distilled acids; 3 ) purification and fractioning in silica columns.

The results of the investigations have shown that in present conditions the most efficient method is that of vacuum distillation. The yield of pure acids is the greater the lesser the amount of impurities in the raw acids.

Academy of Sciences of the Estonian S.S.R., Received Institute of Chemistry 